\title{
CONTRIBUIÇÕES DA TELEVISÃO PARA A FORMAÇÃO DA IDENTIDADE NA ADOLESCÊNCIA - UMA ANÁLISE DO PROCESSO DE RECEPÇÃO
}

TV contribution for the formation and social development of teenagers, a reception study.

Lisa França

Profa. Dra. do Curso de Comunicação da UFG.

E-mail: lisafranza@uol.com.br

Introdução

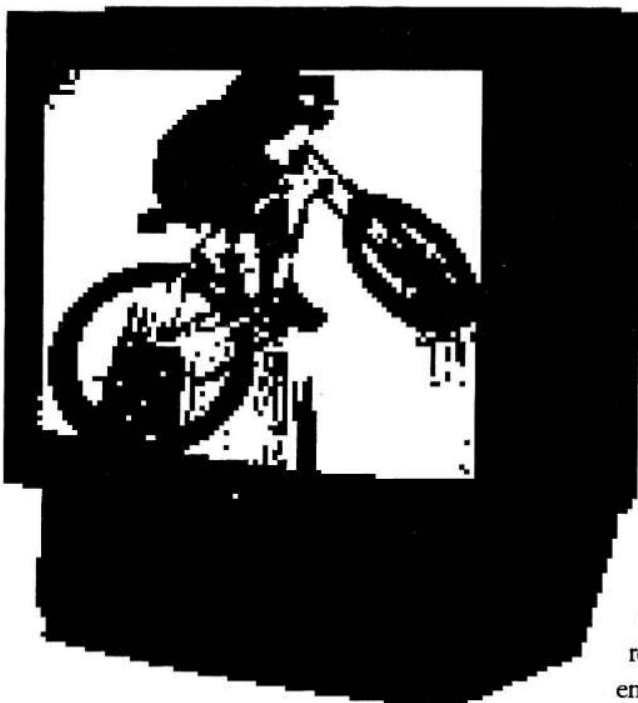

Este trabalho reúne duas grandes paixōes, às quais temos dedicado muitos anos de trabalho e estudo: Psicologia e Comunicaçăo Social, e, nesta, especialmente a televisão, meio no qual atuamos profissionalmente por quase 20 anos. Refletir sobre o próprio trabalho e fazer televisão de qualidade era a preocupação cotidiana que levamos também para a Universidade. Esta pesquisa específica, realizada como trabalho acadêmico para o nosso doutorado, nos permitiu juntar a reflexāo teórica e o experimento empírico para aprofundar a questáo do papel da televisão na contemporaneidade, especialmente no que ela pode contribuir como alimento anímico para adolescentes.

Para nos aproximarmos do tema proposto buscamos informaçốes, inicialmente, em estudos que sugerem que as pessoas, além de usarem a televisão para entender, compreender sua sociedade e extrair opinióes sobre os mais diversos aspectos da vida, empregam o meio para buscar uma identificaçáo com a sociedade e uma identidade para si mesmas: McGuirre, 1974 y 1985; Conway y Rubin, 1991; Bryant y Zillmann, 1996; Becheloni y Buonanno, 1997; Thompson, 1998; Giddens, 1998; Walkerdine, 1998 y Hartley 1999, dentre outros. Também existe um consenso, na psicologia e na psicanálise (Ana Freud, 1975; Erikson, 1972 e 1981; Bettelheim, 1982 e 1995; Coleman, 1985), de que o adolescente passa por profundas crises de identidade e que os anos de adolescência são essenciais para sua formação.

Constatamos ainda que existiam poucas abordagens de conteúdo qualitativo que investigassem as contribuiçôes da televisão para a formação da identidade dos jovens, apesar de a relação público e televisāo estar sendo estudada com profundidade por vários pesquisadores, dos quais destacamos os que estão integrados aos Estudos Culturais Britânicos (especialmente David Morley e Stuart Hall ) e os que pertencem à escola latino-americana (García Canclini, MartínBarbero, M. Inmacolata Lopes, Orozco Goméz), dentre outros.

A Adolecencia como etapa crucial para a formação da identidade

Valorizamos a proposição psicanalítica de que a base para a formaçáo da identidade está na infância e que são importantes os primeiros contatos do recémnascido com seus pais e com o mundo, para a formação de sua identidade. Mas o que propomos aqui é discutir as múltiplas oportunidades de identificar-se consigo mesmo que o indivíduo tem ao longo de sua vida, em concreto durante a crise de identidade da adolescência, quando a questão está particularmente aflorada. Erik Erikson (1972) chama a atençáo para o fato de que na adolescência o indivíduo está muito mais próximo da atualidade histórica do que nos primeiros anos do desenvolvimento infantil. Neste contexto contemporâneo está, sem dúvida, a força da televisão. 
A biologia trabalha com o conceito de puberdade, fase caracterizada pelo crescimento e amadurecimento sexual, para identificar a adolescência. Essa fase, no entanto, não depende apenas da maturação morfológica e fisiológica, mas incide também sobre as questôes emocionais. Por isso trabalhamos com o conceito de adolescência da psicologia que indica que essa etapa do desenvolvimento humano envolve, além das transformaçōes do corpo, o desenvolvimento psicológico e social e que esse período criador e construtivo ocorre dentro de um processo de crise carregado de sofrimento e angústias.

Erikson (1981) produziu uma obra dedicada exclusivamente à crise de identidade na adolescência, na qual defende que o jovem em formação tem várias referências para identificar-se e que incluem não só pessoas reais como também as fictícias, criadas pela literatura, e com as quais os jovens se relacionam por meio de uma relação mediada. No mesmo sentido trabalharam os psicólogos Coleman e Bettelheim. Também o filósofo francês Edgar Morin (1992) defende que a compreensão da dimensāo humana pode fluir da literatura, assim como do cinema, e nós incluiríamos aqui a ficção televisiva, principalmente depois de conhecer a pequena presença que têm a literatura, $o$ cinema e outras formas artísticas de representação do mundo entre as atividades do grupo de adolescentes analisado.

\section{Audiência Adolescente}

Os últimos informes de SOFRES A.M. para o ano $2000^{1}$ indicam que a faixa que menos assiste TV é aquela entre 13 e 24 anos, populaçăo que representa cerca de $10 \%$ do total dos telespectadores na Espanha. Segundo a investigação de Callejo (1995), apesar de ser o grupo social que menos vê televisão, os jovens formam o coletivo que mais seleciona os programas e que mais recorda as grades de programaçáo diárias, além de ser o grupo que menos supervaloriza os conteúdos televisivos.

Os adolescentes espanhóis entre $14 \mathrm{e}$ 18 anos passam, em média diária, 120 minutos frente ao televisor nos dias de semana e até 220 minutos nos fins de semana, segundo pesquisa realizada em 2000 pela
Agrupación de Telespectadores y Radioyentes $^{2}$. A pesquisa, realizada com 2000 adolescentes, atesta que $37,5 \%$ dessa audiência é de séries e filmes e que $7,5 \%$ se dirige aos concursos. Outro informe, do mesmo ano, realizado pela Fundación Santa María sobre hábitos de adolescentes espanhóis, revela que ver televisão, sair ou reunir-se com os amigos, e escutar música gravada são as três principais atividades dos adolescentes espanhóis entre 15 e 24 anos.

\section{A Aproximação do problema}

Depois de ampla pesquisa bibliográfica e empírica, inclusive com instrumentos testados, decidimos trabalhar com alunos matriculados no último ano do Ensino Secundário Obrigatório (ESO), adolescentes de 15 a 18 anos, porque esses adolescentes estavam mais motivados pelas questōes de identidade que queríamos investigar. Como se trata do último ano do ensino obrigatório, os alunos de $4^{\circ}$ de ESO têm de decidir um caminho para suas vidase a carga de reflexão é inevitável. Como não tínhamos os instrumentos para recorrer a uma amostragem representativa dos adolescentes espanhóis, fizemos uma opção por um micro-universo com características homogêneas. Escolhemos, por essa razão, um colégio público na zona central de Barcelona para afiançar uma homogeneidade do grupo social analisado. Era importante assegurar que esses adolescentes tivessem como oferta de consumo televisivo a mesma programação. Sendo todos os adolescentes de uma mesma série, garantia-se também certa uniformidade em termos de conhecimentos cognitivos e capacidade de interpretação e expressão.

Definida a amostragem, aplicamos um questionário inicial para confirmar o consumo mediático, identificar o programa mais visto pelo grupo $e$, ainda, selecionar o programa mais consumido para nossa análise de conteúdo. Depois de um questionário prévio, selecionamos 100 alunos do último ano da ESO. Desse total, 32 deles tinham 15 anos; 33,16 anos; 32,17 anos e 3 haviam acabado de completar 18 anos. O programa mais visto por esse coletivo era a série juvenil semanal Compañeros, produzida em Madrid e ambientada em um colégio com oito
1 Empresa especializada em pesquisas de audiência na Espanha

${ }^{2}$ Fuente $A B C: 20 / 01 / 00$ 
${ }^{3}$ Considerando o horário vespertino e a audiência da época. protagonistas principais, quatro garotos e quatro garotas, que também estariam cursando o último ano do ESO.

Descobrimos que a série não só era a favorita entre os jovens dessa faixa de idade, dessa mesma amostragem homogênea de 100 alunos de um mesmo colégio público de Barcelona, como também era unanimidade nacional, com fãs-clubes registrados em três regiōes distintas do país, com páginas criadas por fās na Internet, que inclusive precederam e inspiraram o site oficial da produção. Soubemos também que Compañeros havia ganhado vários prêmios. Esses fatores nos indicaram que era necessário mais que um olhar crítico de intelectual, mas também humildade para entender por que esse programa específico era o favorito dos adolescentes e estudar como o programa se comunicava com seu público, pois havia que ser considerado esse sucesso para faixa etária tâo crítica e seletiva.

Sobre a análise de conteúdo do programa televisivo

Para esta fase do trabalho, nos baseamos no esquema de Daniel Prieto Castillo (1988) ${ }^{3}$ que sugere que a leitura do discurso televisivo tenha quatro planos: o plano de estrutura básica, que orienta a análise dos aspectos fundamentais colocados em jogo para identificar a intencionalidade da mensagem; o plano narrativo, para a análise dos eixos narrativos nos quais se reconhecem os sintagmas; o plano de análise estilística, para se identificar a relação interna dos enunciados e a comunicação destes na construção do estilo; e o plano ideológico, no qual são colocados o modo de vida que se predica, o modelo de relaçóes e soluçóes sociais, o dito e o oculto.

Criamos, então, uma ficha de análise utilizando o programa informático ACCESS, porque este programa nos permite maiores possibilidades de incluir textos e apreciaçôes, ao mesmo tempo em que nos garante eficiência e rapidez na hora de ordenar e cruzar dados. Gravamos um total de nove capítulos, exibidos durante os meses de maio e junho do ano 2000. A duraçāo de cada emissão variou entre 96 e 103 minutos, incluídos os intervalos comerciais. Acompanhamos a produção do programa, entrevistando os realizadores e produtores, além de recolher dados de audiência, críticas, cartas de leitores e comentários via Internet.

\section{Sobre a análise de recepção}

Somamos à análise da série, a análise da recepçāo, utilizando três técnicas de aproximaçāo com o público adolescente: questionário, redação e grupo de discussão.

O questionário, com perguntas abertas e fechadas, foi a primeira aproximação para identificar o perfil socioeconômico e de consumo de mídia e levantar as questôes básicas sobre a série que iríamos aprofundar na redação e com os grupos de discussāo. Para a análise desse material, trabalhamos com o máximo de rigor, detalhando resposta por resposta, individualmente, e agrupando, posteriormente, a leitura das respostas das meninas separadamente da leitura das respostas dos meninos, quando a questāo nos parecia relevante. Por exemplo, computamos conjuntamente as perguntas que nāo implicavam no fator de gênero, como profissão dos pais, número de irmãos, hábitos de consumo familiar de mídia, e separamos por gênero as respostas sobre as atividades extra-escolares, consumo individual de meios de comunicação e, obviamente, a apreciação da série, assuntos favoritos, identificaçáo com os personagens, etc.

As redaçōes e as discussōes de grupo nos permitiram aprofundar nas questôes mais subjetivas e específicas, para analisarmos o processo de identificação com o programa e o reflexo da série na vida cotidiana desses adolescentes. Escolhemos essas duas técnicas porque acreditamos que a redação feita em casa e individualmente permite uma elaboração maior do pensamento, além de podermos contar com pensamentos mais conclusivos e frases mais bem elaboradas. Decidimos, ainda, complementar o aprofundamento das questôes levantadas na redaçáo com três grupos de cinco adolescentes cada um, porque acreditamos que essa técnica também é um instrumento de valor, por sua capacidade de reproduzir um espaço 
sociocultural que produz sentido para os participantes, facilitando a transparência de emoçôes, cogniçốes e ações. O grupo de discussão também possibilita que o discurso seja analisado no marco de uma relaçáo social, estimulado pelo interacionismo, situaçáo própria da comunicação interativa. A discussão em grupo, por não estar estruturada, traz elementos imprevisíveis que enriquecem a experiência do pesquisador $\mathrm{e}$ questionam suas idéias preconcebidas.

\section{A decodificação e a mediação}

Nos três procedimentos de abordagem, os adolescentes coincidiram em afirmar que a série não lhes parecia ter intenção educativa, mas que, sim, lhes oferecia possibilidades de instruçôes pontuais sobre sexo, drogas, álcool, gravidez, doenças sexualmente transmissíveis e outros temas que, na opiniâo deles, recebem pouca atençāo da escola e da família. Sobre questóes mais subjetivas, como valores e comportamento, os adolescentes nos ofereceram dados que respaldam pesquisas anteriores que atestam que os meios săo mais eficazes em reforçar valores do que transformá-los. (Gerbner y outros, 1980; Morgan, 1982 e 1987; Morgan, Alexander y outros, 1990 e Silverstone, 1996 e 1999).

Agrupamos os temas tratados em macrotemas e constatamos que eles, citados como os mais interessantes na análise de recepçáo, coincidiram de ser também os mais explorados pela série. Esses temas formam parte do cotidiano dos adolescentes e os atraíam por se tratar de experiências que estavam a ponto de viver e/ou que começavam a experimentar (Namoro, Drogas e Sexualidade, principalmente).

Criamos categorias de discurso para analisar o modo como esses temas eram tratados-se com discursos de solidariedade, afeto, conflito, agressão, etc. - e agrupamos, para facilitar a análise, as categorias em discursos positivos e negativos. Tanto os meninos como as meninas escolheram o tema do namoro como o favorito, seguido das histórias de amizade e solidariedade. Entre suas preferências, também figuram o tema das drogas, que esteve presente em cinco dos nove capítulos analisados, e o da sexualidade, discutida em 20,62\% dos diálogos.

Os temas relacionados com o macrotema sexualidade foram tratados de maneira equilibrada. Os discursos negativos, $47,45 \%$ do total, e os discursos positivos representaram 45,76\% dos diálogos. Para a maioria, o tema esteve bem representado, tomando como parâmetro a realidade que vivenciam. Nos grupos nos quais a discussão sobre a questáo foi aprofundada, os adolescentes consideraram positivamente as informaçôes da série sobre o assunto, prevalecendo os discursos de seriedade (positivo) e censura (negativo), aproximadamente equilibrados em todos os temas relacionados com a sexualidade (Gravidez Adolescente, Corpo, e Aborto).

$\mathrm{O}$ tema das drogas ilegais, que os motiva e os interessa, foi considerado bem representado por $83,33 \%$ dos meninos e por $68,42 \%$ das meninas. $O$ assunto foi tratado em 64\% (dos 9 programas analisados coloquei em negrito sobre análise do conteúdo televisivo., na descriçāo metodológica no item anterior ) com discursos positivos, prevalecendo os de seriedade e solidariedade, e em $32 \%$ com discursos negativos. Os adolescentes também se interessaram pelos episódios dramáticos e

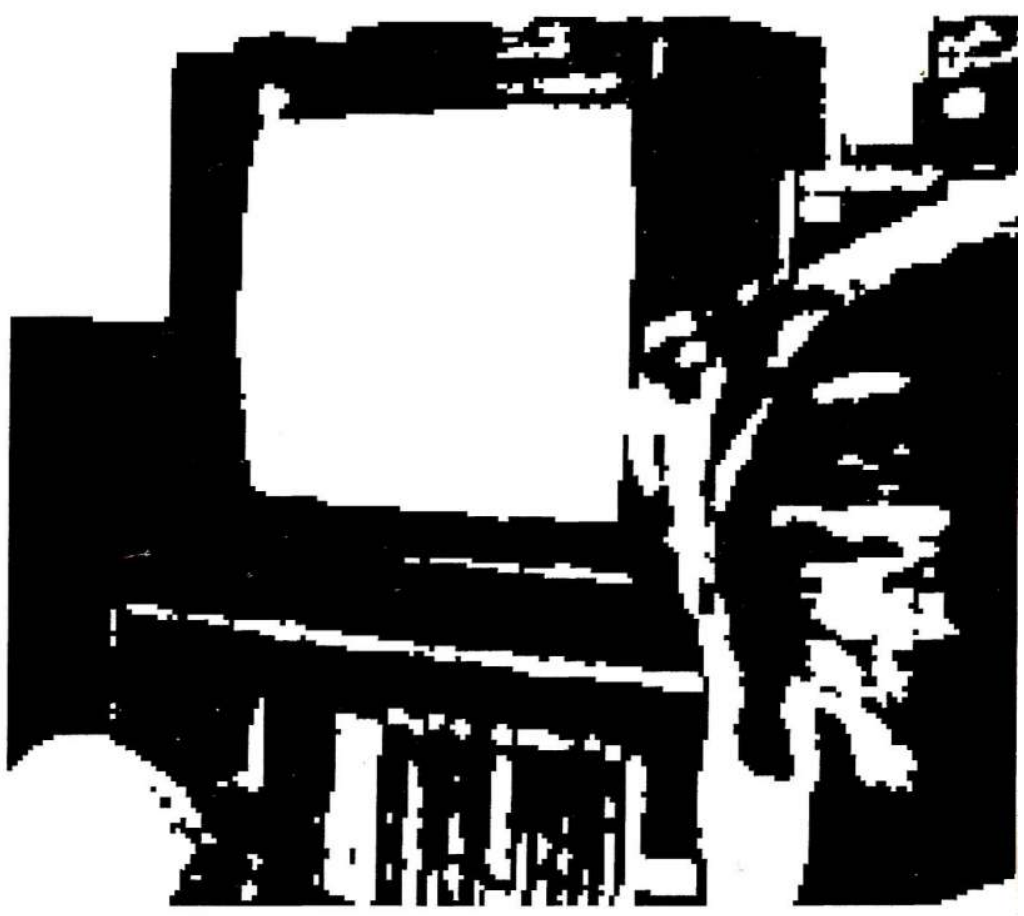




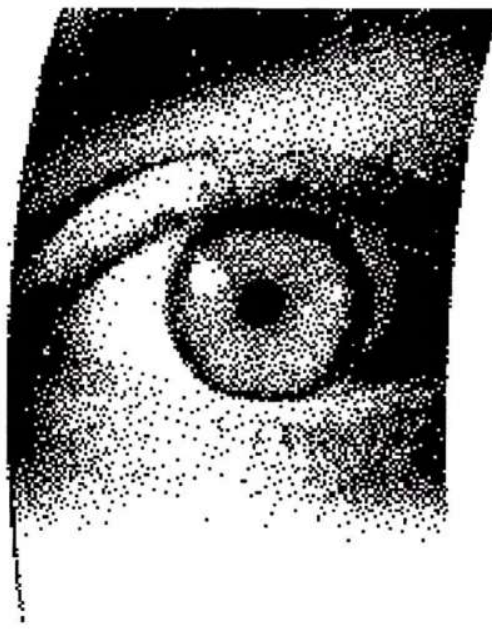

de aventura da série e comentaram as histórias que não os atraíam. Os temas menos valorizados tiveram pouca presença. e foram classificados, na análise de conteúdo, como Outros e representaram 5,94\% do total.

Analisamos também as relaçōes interpessoais. Nos diálogos estabelecidos exclusivamente entre os personagens adolescentes prevaleceram os discursos positivos. $\mathrm{Na}$ análise de recepção, $92,85 \%$ das meninas consideraram que essas relaçóes estavam bem representadas, pareciam-lhes reais porque os personagens se ajudavam e eram solidários entre eles. A proporção de meninos que concordaram com essa afirmaçāo foi de $85,71 \%$. A representaçăo dessas relaçöes foi a que os adolescentes mais identificaram como as melhores retratadas em toda a série.

$\mathrm{Na}$ relaçăo entre adolescentes e pais apresentada na série, $54,16 \%$ dos tratamentos foram com discursos negativos, prevalecendo os discursos de agressão. Nos positivos, prevaleceram os discursos de afeto. Metade das meninas e dos meninos considerou que essas relaçóes estavam "mais ou menos" de acordo com a realidade que vivenciam. E do restante, $28,57 \%$ acharam que essas relaçốes eram bem representadas, enquanto que uma minoria, $14,28 \%$, discordou de que retratassem a realidade.

A série apresentava pais compreensivos e pais que não se entendiam com seus filhos, mas na hora de analisar essas relaçóes poucos adolescentes analisaram os dois aspectos apresentados. Uns adolescentes se fixaram nas relaçóes negativas, outros nas positivas. E uma minoria considerou as duas com muita clareza da representaçáo.

As seqüências que tratavam das relaçōes entre adolescentes e professores estiveram presentes em $16,08 \%$ do total de seqüências analisadas e foram as que mais discursos negativos contabilizaram: $73,91 \%$, nos quais prevaleceram os tratamentos de censura. Mesmo assim, os adolescentes consideraram que eram as relaçóes mais $\mathrm{mal}$ representadas pelo "excesso de confiança". Esta expressão, tal e qual colocada aqui, foi utilizada por muitos dos adolescentes.

Tal contradiçáo entre a apreciação dessas relaçóes e o discurso analisado pode ser explicado pelo desenvolvimento das histórias. Embora houvesse uma predo- minância de discursos de enfrentamento e censura, normalmente os conflitos eram resolvidos de maneira positiva com acordos ao final, e essa impressão pareceu prevalecer. De fato, nas relaçôes representadas entre professores e alunos, a maioria dos diálogos foi de enfrentamentos, mas a recepção considerou que essas relaçōes não estavam bem representadas na série, exatamente pelo motivo contrário. Apesar de a audiência estudada concordar em que essas relaçóes são as mais mal representadas, no que concerne a suas conexốes com a realidade, essa representação encontra eco no imaginário de alguns adolescentes que, apesar de considerarem essas relaçóes fora da realidade, valorizavam o que elas tinham de idealizadas. Computamos discursos nesse sentido nas redaçōes e nos grupos, inclusive por repetição de termos e coincidência de expressóes, tais como "o professor tem de ajudar os alunos"; "mais bem são professores de nossos sonhos...", "não estaria mal se fosse assim"...

\section{Conclusões}

Entendemos que os paradoxos e as incoerências plasmadas em alguns resultados formam parte da natureza do trabalho qualitativo e das idiossincrasias do ser humano. Não acreditamos que uma análise de um número maior de capítulos da série ou uma amostra mais ampla neste estudo de recepção pudesse gerar dados mais homogêneos.

Gostaríamos de destacar o consumo por imitação. Como já citamos anteriormente, o adolescente faz parte de um coletivo que vê pouca televisão e é mais seletivo, mas sua necessidade gregária o impulsiona a um consumo de televisão por imitação, no marco de seu grupo. Isso resulta evidente no consumo generalizado de séries televisivas e de programas que entram na moda, como o caso do Big Brother (também realizado na Espanha por ocasião da pesquisa). $\mathrm{O}$ consumo por imitação de produtos culturais é só mais um dentre o consumo de outros produtos industriais.

Dentre as conclusōes mais significativas podemos destacar:

As séries juvenis de televisão são fonte de informaçăo e de formação de valores, 
contribuem com idéias que são aproveitadas pelos adolescentes para a construção de suas identidades.

A televisão é, para os adolescentes pesquisados, além de fonte de informaçāo, diversão e ócio, um alimento anímico buscado para ampliar e organizar sua vivência psíquica e afetiva. No entanto, os comentários, quando contrastados com os dados do questionário sociomediático, evidenciavam que quanto mais informado é o adolescente, quanto mais maduro seu pensamento, maior sua capacidade para uma recepção crítica das mensagens mediáticas em geral. Encontramos interpretaçōes completamente antagônicas do mesmo conteúdo televisivo e o jovem receptor remitia à sua experiência pessoal como ponto de referência.

As séries juvenis de televisão proporcionam aos adolescentes a expansão de recursos simbólicos que empregam na formação de suas identidades. As séries também oferecem aos adolescentes possibilidades, horizontes e pontos de referência simbólica, que seráo incorporados a seus valores e opiniōes.

Fica claro que uma série juvenil de televisão de êxito, como é o caso de Compañeros, oferece aos adolescentes informaçóes e vivências que os ajudam a refletir sobre sua própria vida. É o alimento psicológico, mais do que informaçóes concretas, que os adolescentes buscam na audiência da série. A análise da recepção mostrou que a mostra despreza os anúncios comerciais e a presença do merchandising, e busca aspectos mais subjetivos, que os ajudem a organizar sua vivência psíquica, nessa fase conflitiva e de incertezas.

A expansão dos recursos simbólicos é evidenciada pelos relatos dos processos de identificação com os protagonistas. Os mecanismos de identificação descritos demonstram que os personagens passam a formar parte do universo afetivo e de referência da audiência. Essa implicação pessoal é observada também no desprezo pelas seqüências nas quais aparecem as rupturas amorosas e pelos episódios mos quais os personagens têm modificado seu comportamento usual.

As séries juvenis de televisão sugerem possibilidades de atuação social aos jovens.
Estes, apoiados na reflexão, as utilizam como modelos a seguir.

As séries de ficçảo incrementam o número e o tipo de relaçôes que os adolescentes são capazes de estabelecer, porque oferecem modelos de relaçôes das quais os adolescentes podem estar privados por alguma razão. Em função da vivência pessoal do adolescente, esses modelos de relaçôes parecem-lhes mais ou menos credíveis e os impactam de forma diversa. Nosso estudo nos permite assegurar que os adolescentes utilizam como modelos o modo de vestir e de usar o cabelo dos personagens (imagem pessoal), embora, na nossa pesquisa, o jovem adolescente justificasse sua identificaçâo com os personagens por meio das suas atuaçōes e comportamentos, enunca por razōes de identificaçāo com o tipo físico ou a forma de se apresentar dos personagens.

A recepção televisiva é pessoal e única, mas observam-se algumas coincidências em gênero e grupos.

Essa hipótese foi confirmada ao longo de todo o trabalho qualitativo, em que se sobressaíram interpretaçốes originais, difíceis de enquadrar em marcos gerais. Existem coincidências entre as interpretaçōes femininas e masculinas nas questôes globais (apreciação da série e macrotemas/temas favoritos), mas diferenças de gênero surgem ao nos aprofundarmos nas análises dos personagens, nas análises da interpretaçāo das relaçóes e nas decodificaçóes da linguagem televisiva.

Apesar do número equilibrado de meninos e meninas fās da série, muda a identificação com os personagens e o gosto pela estética formal do programa, como as inovações técnicas que motivam muito mais os meninos que as meninas. Acreditamos que na interpretaçăo intervêm, além de variáveis de gênero, a história pessoal de cada adolescente, suas convicçóes morais e ideológicas e as características psicológicas dos receptores.

\section{Considerações Finais}

Este trabalho nos garante, uma vez mais, que o impacto da recepção televisiva e suas decodificaçōes não são comuns a toda 
recepção. Por isso, entendemos e compartimos a inquietude por uma reflexão sobre os conteúdos televisivos. Sabemos que as crianças e os adolescentes são mais vulneráveis à experiência televisiva e isso tem de ser levado em consideração ao elaborarem-se programas específicos para essas faixas de idade.

Cónsideramos legítima a preocupaçāo de se ensinar os códigos dos meios como parte da educaçăo formal no Brasil. Deveria fazer parte do ensino básico, como fazem parte da educação formal outras técnicas de sobrevivência. Trata-se de um sobreviver em um mundo mediatizado. Para poder defender-se de mensagens ideológicas nocivas (sejam publicitárias ou não), é necessário que a criança e o adolescente tenham seu sentido crítico estimulado e possam conhecer todas as engrenagens da produção televisiva, desde a lógica comercial até as possibilidades de manipulaçóes tecnológicas.

\section{Abstract:}

This article brings the contribution of Psychology, Cultural Studies and Social Communications Theories to the analyses of TV reception. It also presents the methodology steps of a research done with a hundred teenagers who followed a TV youth program in Barcelona at the year 2000, besides an analyses of the series so the investigator would have the hints of how it affected the reception. The work embraces the media, TV and reception with emphasis in the mediation process. TV contribution for the formation and social development of teenagers, a reception study.

key words: psychology, television, teenagers, culture, reception, youth TV programs.

\section{Bibliografia}

BECHELLONI, G. y BUONANNO, M. (1997): Television Fiction and Identities. Firenze, Itália. Ipermedium.

BETTELHEIM, B. (1982): Educación y Vida Moderna, un enfoque psicanalítico. Barcelona, Ediciones Crítica.
BETTELHEIM, B. (1995): Psicoanálisis de los Cuentos de Hadas. Barcelona, $2^{\circ}$ edición, Crítica.

BRYANT, J y ZILLMANN, D. (1984): Using television to alleviate boredom and stress. In Journal of Communication (29)1 (1999).

BRYANT, J.; ZILLMANN D. copiladores (1996): Los efectos de los medios de comunicación - Investigaciones y teorías. Barcelona, Paidós.

CALLEJO Galego, J. (1995): La audiência activa. El consumo televisivo: discursos e estratégias. Madrid. Centro de Investigaçóes Sociológicas.

CASTILLO, Daniel Prieto (1988): Análisis de Mensajes. Quito, Ciespal.

COLEMAN, J.C. (1985): Psicología de la adolescencia. Madrid, Ediciones Morata.

CONWAY, J. y RUBIN, A (1991): Psychological Predictors of Television Viewing Motivantion, En García Muñoz (1996) Comportamientos y hábitos de consumo televisivo del niño en el ámbito familiar, TD Departament de Comunicació Audiovisual i Publicitat Universitat Autónoma de Barcelona.

ERICKSON, E. (1970): Infancia y Sociedad. Buenos Aires, Ediciones Hormé S.A.E.

ERICKSON, E. (1972): Sociedad y adolescencia. México, Siglo XXI editores, S.A.

ERICKSON, E. (1981): Identidad, Juventud y crisis. Mardid, Taurus Ediciones.

FREUD, A. (1975): Normalidad y Patología en la Niñez, evaluación del desarrollo. Buenos Aires, editora Paidós.

FREUD, S. (1937): The Ego and the Mechanisms of Defense. Londres, Hogarth Press.

GARCÍA CANCLINI, N. (1990): Culturas Hibridas. México, Grijalbo.

GARCÍA CANCLINI, N. (1995):

Consumidores e cidadãos. Rio de Janeiro, Editora UFRJ.

GARCÍA CANCLINI, N. (1996):

Consumo Cultural y medios. México,

Universidad Nacional de la Palta.

GARCIA CANCLINI, N. (1997): Cultura

y Comunicación: Entre lo global y lo local.

Argentina, Ediciones de Periodismo y

Comunicación, Universidad Nacional de La

Plata.

GERBNER, G. et al (1980), En

BRYANT, J. y ZILLMANN, D.(1996): 
Los efectos de los medios de comunicación - Investigaciones y teorías. Barcelona, Paidós. GERBNER, G. (1972): Violence in Television drama: Trends and symbolic functions, en G. A. Comstock y E. Rubinstein (1998): Television and social behavior: vol I Media and Control. Washington, Government Printing Office. GIDDENS, A. (1998): Modernidad e identidad del yo. Barcelona , $2^{a}$ edic. Península.

HALL, S.; DU GAY, P. (1996): Questions of Cultural Identity. Londres, Sage.

HALL, Stuart. (1981): Encoding/decoding in television discourse. Londres, Hutchinson. LOPES, M. I. (1993) Estratégias metodológicas da pesquisa de recepçāo. Intercom. Revista Brasileira de municação, Vol XVI,2. São Paulo.

LULL, J. (1990): Inside family viewing. Ethnographic research on television's audiences. Londres y Nueva York, Routledege Edt.

LULL, J. (1992): La estructuración de las audiencias masivas. Madrid, Dialogos de la Comunicación, 32.

MARTIN BARBERO, J. (1987): De los Medios a las Mediaciones. Barcelona, México, Editorial Gustavo Gili.

MARTÍN-BARBERO, J. (1990): De los medios a las práticas. En: "La comunicación desde las práticas sociales: reflexiones en torno a su investigación". Cuadernos de Comunicación y Práticas Sociales, n. 1, México: Universidad Iberoamericana.

MARTIN-BARBERO, J. y MUÑOZ, S. (coordenadores), (1992): Televisión y melodrama. Bogotá, Tercer Mundo.

MORGAN, M. y otros (1990): International cultivation analysis En New directions in media effects research, Newbyry Park, Ca, Sage, pp 225-248.

MORGAN, M. (1987): Televisión, sex-roles attitudes, and sex-role behavior, en Journal of Early Adolescence 7 (3), pp.269-282.

MORGAN, M. (1982), Television and adolescents, sex-role stereotypes: A longitudinal study, journal of Personality and Social Psychology 43 (5), pp. 947-955. MORGAN yALEXANDER et al (1990) En BRYANT, J. y ZILLMANN, D.(1996): Los efectos de los medios de comunicación Investigaciones y teorías. Barcelona, Paidós, en Public Opinion Quartely, 44, pp 408410 .
McGUIRE, W. (1974): Psychological motives and communication gratification, En García Muñoz (1996): Comportamientos y hábitos de consumo televisivo del niño en el ámbito familiar, TD, Departament de Comunicació Audiovisual i Publicitat, UAB.

McGUIRE, W. (1985): Attitudes and attitude Change, En García Muñoz, (1996): Comportamientos y hábitos de consumo televisivo del niño en el ámbito familiar, TD, Departament de Comunicació Audiovisual i Publicitat, UAB.

McGUIRE, W. (1986): The myth of massive media impact: Savaging and salvaging, En Albert Bandura (1996): Teoría social cognitiva de la comunicación de masas, San Francisco, Stanford.

MORIN,E. (1992): El método. Las ideas. España, Cátedra.

MORLEY, D. (1980): The Nationwide Audience: structure and decoding. Londres, British Film Institute.

MORLEY, D. (1986): Family Television: cultural power and domestic leisure. Great Britain, Comedia.

MORLEY, D. (1992): Television, Audiences \& Cultural Studies, Londres, Routledge.

MORLEY, D. (1998): Populismo, revisionismo y los "nuevos estudios de audiencia pp 417 a 437 En Morley et al (1998): Estudios culturales y comunicación: análisis, producción y consumo cultural de las políticas de identidad y el posmodernismo. Barcelona, Paidós.

OROZCO, G. (1991): Recepción televisiva. Tres aproximaciones y una razón para su estudio. Cuadernos de Comunicación y Practicas Sociales, (2).

OROZCO, G. y VARGAS, H.(1994): Televisón, niños y mediaciones. México, Universidad Iberoamericana.

SILVERSTONE, R. (1996): Televisión y vida cotidiana. Buenos Aires, Amorrortu. THOMPSON, J. B. (1995): Ideologia e cultura moderna. Petrópolis, Vozes.

THOMPSON, J.B.(1998): Los Media y la modernidad. Barcelona, Ediciones Paidós Ibérica.

WALKERDINE, V.(1998): Estudios Culturales y comunicación - análisis, producción y consumo cultural de las políticas de identidad y el posmodernismo. Barcelona, Paidós. 